\title{
EOR of Spontaneous Imbibition by Surfactant Solution for Tight Oil Reservoirs
}

\author{
Anqi Shen ${ }^{\mathrm{a}}$, Yikun Liu ${ }^{\mathrm{a}}$, Shuang Liang, ${ }^{\mathrm{a},}$, Fengjiao Wang ${ }^{\mathrm{a}}$, Bo Cai $^{\mathrm{b}}$, and Yuebin Gao ${ }^{\mathrm{b}}$ \\ ${ }^{a}$ Key Laboratory of Enhanced Oil and Gas Recovery of Education Ministry, Northeast Petroleum University, Daqing, 163318, China \\ ${ }^{b}$ Research Institute of Petroleum Exploration and Development (Langfang), Langfang, 065007, China
}

\begin{abstract}
Spontaneous imbibition has been well investigated due to its impacts on oil recovery in conventional and fractured reservoirs. Differentiated in relation to the conventional reservoir, the tight reservoir is characterized by its ultra-low porosity and permeability. The scope of current research is to study the mechanism of imbibition under conditions of tight cores and surfactant solution. A series of experiments was conducted to determine the effects of tight core imbibition including three kinds of common surfactant solutions. The main factors of low IFT (interfacial tension) and wettability alteration are examined. The experimental results indicate that the original wettability affects the imbibition oil recovery, since low IFT and wettability alteration constitute beneficial parameters for imbibition as it concerns adhesive work reduction. The parameter of $N_{B m^{-1}}$ was not applied for optimal IFT or CA (contact angle) calculation concerning porous media with reduced capillary scale. Future research concerning the imbibition mechanism should take the property of surfactant into account.
\end{abstract}

Keywords: tight oil reservoir; imbibition; wettability; low IFT; surfactant solution

(Submitted on March 13, 2018; Revised on April 29, 2018; Accepted on June 3, 2018)

(C) 2018 Totem Publisher, Inc. All rights reserved.

\section{Introduction}

Unconventional reservoirs have become an increasing research area of interest in oil and gas exploration, due to the sufficient development of hydraulic fracturing and the horizontal drilling technique. This technique allows for production at the commercial-flow rate through the creation of a flow path [1]. Tight oil reservoirs play a major role in the development of unconventional oil and gas resources. In this case, the nano-scale channels and pores already exist, and hydrodynamic effects such as flooding are limited. Therefore, imbibition has emerged as an effective way to aim the residual oil in an oilcontaining matrix of tight reservoirs following fracturing. Spontaneous imbibition refers to the invasive process in porous media, in which a wetting phase displaces a non-wetting phase by means of capillary and/or gravity forces [2]. In a waterwet reservoir, the injected aqueous phase will invade the matrix spontaneously in an oil-wet or mixed-wet reservoir, and the wettability alternation agent causes imbibition. As long as the oil enters fractures by the effect of imbibition and under the effect of natural pressure or mechanical lifting, the oil is delivered to the ground through fractures of higher seepage capacity. This kind of technique is called "quasi-natural energy development". Thus, promoting the imbibition between the matrix and fractures will increase the total oil recovery of tight oil. Figure 1 illustrates the exchange process of the aqueous and oil phases between the fracture and matrix, during imbibition in a tight reservoir and after fracturing.

For decades, research groups have studied the imbibition mechanism. As it concerns the recovery mechanisms of imbibition and gravity segregation in low IFT solution, it was demonstrated that the reduction of IFT may improve or limit the rate of imbibition, which depends on the relation between capillary and gravity [3]. An in-depth analysis of the imbibition mechanism was conducted based on laboratory experiments, and the authors proposed the innovative dimensionless number $N_{B}^{-1}$, expressed in Equation (1) [4].

\footnotetext{
* Corresponding author.

E-mail address: liangshuang21@163.com.
} 


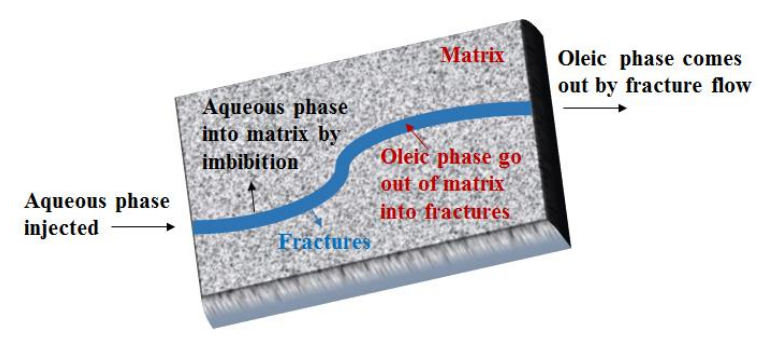

Figure 1. Diagram of imbibition flow between fracture and matrix

$$
N_{B}^{-1}=C \frac{\sigma \sqrt{\phi / k}}{\Delta \rho g H}
$$

where $C$ represents the constant of porous medium geometry, $C$ equals 0.4 concerning the cylinder capillary, $\sigma$ stands for interfacial tension between the oil and aqueous phases $(\mathrm{mN} / \mathrm{m})$ and equals the porosity, $\mathrm{k}$ is the medium permeability $\left(\mathrm{cm}^{2}\right)$, $\mathrm{g}$ is gravity acceleration $\left(\mathrm{cm} / \mathrm{s}^{2}\right), \mathrm{H}$ equals the core length $(\mathrm{cm})$, and $\Delta \rho$ represents the density difference between two immiscible phases $\left(\mathrm{g} / \mathrm{cm}^{3}\right)$. Furthermore, it was denoted that gravity dominated co-current flow when $N_{B}{ }^{-1}<0.2$ and capillary force dominated counter-current imbibition when $N_{B}{ }^{-1}>5$. A modified $N_{B}{ }^{-1}$, represented by $N_{B m}{ }^{-1}$, was proposed 15 years later by Yao et al. [5,6] which included the wettability factor and was defined as Equation (2).

$$
N_{B m}{ }^{-1}=\mathrm{C} \frac{2 \sigma \cos \theta \sqrt{\phi / k}}{\Delta \rho g H}
$$

where $\theta$ represents the $\mathrm{CA}\left(^{\circ}\right)$. Most of the past research on the imbibition mechanism was based either on experiments or mathematical models and is also mentioned in the following literature.

In addition to mechanism research, the scaling method and enhancement of imbibition recovery are both promising methods in the study of imbibition. A scaling law of imbibition was initially proposed and verified through experimental results [6]. The imbibition recovery was calculated based on the triple exponential functions [7]. Wang et al. [8] established the scaling law of surfactant imbibition rate for fractured shale formation, and it was demonstrated that the surfactantimbibition would proceed more than a few meters into the low-permeability shale/chalk formation. To enhance oil recovery of spontaneous imbibition in a tight matrix, many researchers have proposed the effects of wettability alteration and low IFT. In 1993, Keijzer [9] proposed that miscible fluids can induce imbibition and that the surfactant imbibition is not driven by equilibrium interfacial tension. Additionally, they proposed that surfactant affects imbibition rate but has an insignificant effect on the ultimate recovery of imbibition. The most suited surfactant formulations were discovered by laboratory studies, concerning imbibition improvement from oil shale in Bakken (US). Furthermore, the wettability of Bakken was determined through Amott tests [10,11]. Imbibition experiments on mineral plates were carried out including eight anionic surfactants and three nonionic surfactants, and they confirmed that oil recovery increases as wettability alteration increases [12]. A surfactant formulation was proposed to enhance oil recovery of oil-wet rocks at high temperature, high salinity, and hardness reservoir conditions [13]. Computed tomography (CT) is always used in imbibition studies. Berg [14] studied the oil mobilization and nonwetting-phase distribution. Mirzaei [15] carried out the surfactant imbibition by using oil-wet cores of different sizes and CT scans and proposed a new scaling method. Alshehri [16] discussed imbibition of carbonates both in vertical and horizontal orientations with and without surfactant, by using experiments and CT. Alvarez1 carried out spontaneous imbibition experiments with modified Amott cell and concluded that anionic surfactant achieved more efficient oil production than the nonionic and cationic surfactant. The surfactant-enhanced effects of low IFT and wettability alteration were studied using fractured carbonates $[13,17]$. In terms of mathematical models, Chen presented one- and twodimension analytical solutions for countercurrent imbibitions [18]. Gautam et al. demonstrated an imbibition model with the presence of fracture fluid flow using the droplet detachment model [19]. Most of the past research concerning the analytical or numerical model of imbibition is based on the nonlinear diffusion equation [20,21,22,23,24]. The numerical model of imbibition considering the effects of surfactant, which are wettability alteration and IFT, were also established [25, 26]. Nevertheless, the effects of surfactant imbibition on tight reservoirs represent an innovative research area. This paper focuses on the determination of the effects of low IFT and wettability alteration on the process of imbibition in tight reservoirs through imbibition experiments of artificial tight sandstone. Furthermore, the main driving force and mechanism of imbibition in a porous medium with nano-scale pores were analyzed. Overall, this work contributes to the definition of mechanism control of the oil recovery of unconventional imbibition, which is important for the optimization of the selection of fracturing fluid to enhance the recovery rate. 


\section{Materials and Methods}

\subsection{Materials}

The chemicals used for the surfactant solutions consist of: two kinds of commercial anionic surfactant, petroleum sulfonate (PS) and dodecyl benzene sulfonate (DBS), by Daqing Donghao (China); and an ampholytic surfactant, alkyl betaine (AB), by Shanghai Nuosong (China). The surfactants were dissolved in formation brine with a salinity of $3589 \mathrm{mg} / \mathrm{L}$ to a final concentration of $0.15 \mathrm{wt} \%$. The brine composition is presented in Table 1. The IFT between brine and oil corresponds to $33.47 \mathrm{mN} / \mathrm{m}$. Simulated oil was prepared with actual crude from Daqing Oilfied and kerosene, with a density of $0.89 \mathrm{~g} / \mathrm{cm}^{3}$ and a viscosity of $3.0 \mathrm{mPa} . \mathrm{s}$ at $45^{\circ} \mathrm{C}$.

All the cores used in this study were obtained from artificial core preparation laboratory (Enhanced Oil and Gas Recovery Laboratory of Northeast Petroleum University). The artificial tight core was made of quartz $\mathrm{sand}\left(\mathrm{SiO}_{2}\right)$ and epoxy resin with ultra-low permeability and porosity. The cores used for the spontaneous imbibition experiments were cylindrical with a diameter of $2.5 \mathrm{~cm}$ and a height of approximately $5.0 \mathrm{~cm}$. The standard cylindrical artificial core is $10 \mathrm{~cm}$ in length, and then we cut the core in half with each half having a length of $5 \mathrm{~cm}$. Each of the halves (with the same properties) were used in the same experiment as mutual verification, and the experimental result is the average of the two half cores $(5 \mathrm{~cm})$. Properties of the cores are given in Table 2.

Table 1. Formation brine composition

\begin{tabular}{|c|c|c|c|c|c|c|c|c|}
\hline Ion & $\mathrm{Na}^{+}+\mathrm{K}^{+}$ & $\mathrm{Ca}^{2+}$ & $\mathrm{Mg}^{2+}$ & $\mathrm{SO}_{4}{ }^{2-}$ & $\mathrm{Cl}^{-}$ & $\mathrm{CO}_{3}{ }^{2-}$ & $\mathrm{HCO}_{3}{ }^{-}$ & Total \\
\hline $\operatorname{Mass}(\mathrm{mg} / \mathrm{L})$ & 1196 & 13 & 36 & 42 & 1182 & 1 & 1120 & 3589 \\
\hline
\end{tabular}

Table 2. Core properties

\begin{tabular}{|c|c|c|c|c|c|c|c|}
\hline Core No. & $\begin{array}{c}\text { Pore volume } \\
\text { PV }(\mathrm{ml})\end{array}$ & $\begin{array}{c}\text { Porosity } \\
(\%)\end{array}$ & $\begin{array}{c}\text { Permeability } k \\
\left(10^{-3} \mu \mathrm{m}^{2}\right)\end{array}$ & $\begin{array}{c}\mathrm{CA} \\
\theta\left({ }^{\circ}\right)\end{array}$ & $\begin{array}{c}\text { Brine } \\
\text { saturation } \\
S_{w i}(\%)\end{array}$ & $\begin{array}{c}\text { Oil saturation } \\
S_{o i}(\%)\end{array}$ & $\begin{array}{c}\text { Saturated oil volume } \\
(\mathrm{ml})\end{array}$ \\
\hline 1 & 3.08 & 13.9 & 1.41 & 61.8 & 73.86 & 26.14 & 0.891 \\
\hline 2 & 3.12 & 13.9 & 1.10 & 60.7 & 74.03 & 25.97 & 0.886 \\
\hline 3 & 3.04 & 13.1 & 1.10 & 68.7 & 73.33 & 26.67 & 0.857 \\
\hline 4 & 2.98 & 13.2 & 1.13 & 66.1 & 74.07 & 25.93 & 0.840 \\
\hline 5 & 3.11 & 13.7 & 1.18 & 114.2 & 73.97 & 26.03 & 0.875 \\
\hline 6 & 3.01 & 13.7 & 1.12 & 118.6 & 74.73 & 25.27 & 0.849 \\
\hline 7 & 3.00 & 13.5 & 1.08 & 113.6 & 74.19 & 25.81 & 0.855 \\
\hline 8 & 3.03 & 13.9 & 1.05 & 119.7 & 73.89 & 26.11 & \\
\hline
\end{tabular}

\subsection{Interfacial Tension (IFT) Measurements}

The IFT between the surfactants solution $(0.15 \mathrm{wt} \%)$ and oil phase were measured by using the spinning drop method by an interfacial tensiometer (TX-500C, Shanghai Zhong-Chen, China) at $45^{\circ} \mathrm{C}$ and the rotation speed equaled $5000 \mathrm{r} / \mathrm{min}$. The IFT measuring technique can be described as: following the surfactant solution preparation, the solution was injected into the test tube using needle tubing. Subsequently, an oil drop of approximately $2 \mu \mathrm{L}$ was injected into the test tube. Authors ensured that no air was injected into the test tube and the test tube cap was tightened. By launching the IFT measurements, the length and width of the oil drop were recorded every $20 \mathrm{~min}$. The representation of the oil droplet measurement is illustrated in Figure 2. As long as the difference of the droplet size following three consecutive measurements is less than $0.1 \mu \mathrm{m}$, then the droplet morphology is stable, and the moment of interfacial tension is calculated using Equation (3).

$$
\sigma=(1 / 8) \times \pi^{2} \cdot \Delta \rho \times 10^{16} \cdot\left(d^{3} / m^{3}\right) \cdot\left(1 / n^{3}\right) \cdot\left(1 / R^{2}\right) \cdot f(L / d)
$$

where $\sigma$ refers to IFT $(\mathrm{mN} / \mathrm{m}) ; \Delta \rho$ corresponds to the density difference of the two tested phases $\left(\mathrm{g} / \mathrm{cm}^{3}\right) ; R$ represents the rotation speed $(\mathrm{ms} / \mathrm{r})$; $\mathrm{n}$ depicts the refractive index; $\mathrm{d}$ equals the width of oil droplets $(\mathrm{cm})$; $\mathrm{m}$ refers to microscope magnification; and $f(L / d)$ stands for the correction factor. When $L / d \geq 4$, then $f(L / d)=1$, and this represents the measuring condition in this paper (oil droplets rotate and stretch to $L / d \geq 4$ ).

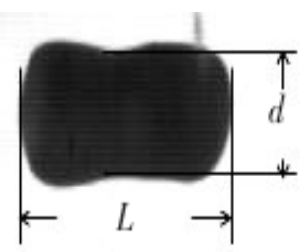

Figure 2. Schematic of oil droplet measurement 


\subsection{Contact Angle Measurements}

The common methods of quantitative characterization for wettability correspond to CA and wettability index (WR). Furthermore, nuclear magnetic resonance (NMR) or relative permeability curve (RPC) is adopted to qualitative analysis. Under the conditions of low porosity and permeability in tight reservoirs, methods such as WR and RPC are limited for wettability calculation, due to the difficulty of fluid flowing through the cores. Thus, the CA measuring method is preferable for tight cores [1]. According to CA, wettability can be divided into water-wet $\left(<75^{\circ}\right)$, intermediate-wet $\left(75^{\circ} \sim 105^{\circ}\right)$ and oil-wet $\left(105^{\circ} \sim 180^{\circ}\right)$ [27].

Surfactant solutions were tested for wettability alteration. To alter the wettability of the artificial tight cores, they were primarily aged in crude oil for days at reservoir temperature $\left(45^{\circ} \mathrm{C}\right)$. As expected, the aging altered wettability, since the cores turned out to be more oil-wet as the aging time increased [12]. Then, the cores were immersed in the surfactants solution for 2 days, and the CA between cores and brine was tested using an optical CA measuring device (DSA100, Krüss Company, Germany). The procedure of CA measuring is as follows:

(1) The artificial core's surface is smooth polished. The titration volume of micro syringe needle was set to 2.750 $\mu \mathrm{L}$, and the pretreated core was installed in the sample stage. The sample stage was moved to let the core pick up the liquid from the needle (distilled water) while the camera was used for recording.

(2) The image records on the computer were checked, and the baseline was set. The drop contour was observed on the image, and the CA was obtained by function fitting. The valid result was selected, while the system error of the result was not more than $5 \%$.

(3) Three different measurement points were randomly selected on the same core, by considering the average of three valid results, such as the core's CA. The CA was tested in the same way, before and after wettability alternation.

\subsection{Spontaneous Imbibition Assays}

The spontaneous imbibition assays were carried out with artificial tight cores, sealed containers, and electronic balance. The tight cores where weighed after vacuuming and drying and were saturated with brine. Their wet weight was measured, and then they were saturated with simulated oil. During the imbibition assays, the oil-saturated cores were immersed in the container filled with surfactant solution and hung on one end of the balance. The cores absorbed the aqueous phase and expelled the oleic phase out, due to the difference between oil and water density. Thus, the quality of cores will increase, and the electronic balance was adjusted to weigh the cores' quality. The cores' weight during imbibition was measured using an electronic balance with a repeatability of $\pm 10^{-3} \mathrm{~g}$. The recovery of imbibition is calculated in Equation (4).

$$
R=\frac{\Delta m}{\left(\rho_{\mathrm{w}}-\rho_{\mathrm{o}}\right) V_{\mathrm{o}}}
$$

In Equation (3), $R$ refers to oil recovery; $\Delta m$ corresponds to changes in the core weight $(\mathrm{g}) ; \rho_{w}$ and $\rho_{o}$ equal the density of water and oil respectively $\left(\mathrm{g} / \mathrm{cm}^{3}\right)$; and $V_{o}$ stands for the volume of saturated oil $\left(\mathrm{cm}^{3}\right)$.

\subsection{Experimental Procedures}

There are 4 main experimental parts: IFT measurement, CA measurement, core saturation and spontaneous imbibition. The IFT and CA measurements were repeated three times and the average of the three measurements was used as the result. The description of the main experiments in this paper is presented in Table 3.

Table 3. Experimental description

\begin{tabular}{|l|l|l|}
\hline \multicolumn{2}{|c|}{ Table 3. Experimental description } \\
\hline Experiments & Measuring method & Experimental Device \\
\hline IFT measurement & Spinning drop & TX-500C, produced by Shanghai Zhong-Chen Company, China \\
\hline CA measurement & Pendant drop & DSA100, produced by Krüss Company, Germany \\
\hline Core saturation & Saturated under high pressure & Core flooding device, Haian petroleum technology co. LTD, China \\
\hline Spontaneous imbibition & Weighing method & Self-designed \\
\hline
\end{tabular}


The imbibition experiment mainly consisted of the core saturation and spontaneous imbibition. Unlike conventional injection, a higher pressure is needed in the process of core saturation. Thus, the ambient pressure was $30 \mathrm{MPa}$. The experiments were carried out under a temperature of $45^{\circ} \mathrm{C}$, which corresponds to the reservoir temperature in the Daqing tight oil reservoir. The core saturated experimental procedures are as follows: a vacuum is created in the core, which is saturated with water. The water permeability was calculated. Approximately $3.0 \mathrm{~cm}^{3}$ of water was injected into the cores, at a rate of $0.05 \mathrm{~cm}^{3} / \mathrm{min}$. Then, the core was saturated with oil, and the oil saturation was calculated. Approximately $0.85 \sim 0.90 \mathrm{~cm}^{3}$ of oil was injected into the cores, at a rate of $0.05 \mathrm{~cm}^{3} / \mathrm{min}$.

\section{Results and Discussion}

\subsection{Effect of Wettability on Imbibition Recovery}

Complete experimental results of imbibition are presented in Table 4. $\theta$ and $\theta^{*}$ correspond to the CA before and after the wettability alteration. Figure 3 illustrates the plot of oil recovery and time. The water-wet cores have higher recovery compared to the oil-wet cores, whether or not the same kind of surfactant solution was used. The tight cores, both of waterwet and oil-wet, do not produce any oil in brine.

\begin{tabular}{|c|c|c|c|c|c|c|c|c|}
\hline Wettability & $\begin{array}{c}\text { Core } \\
\text { No. }\end{array}$ & $\theta\left({ }^{\circ}\right)$ & $\theta *\left({ }^{\circ}\right)$ & $\sigma(\mathrm{mN} / \mathrm{m})$ & Imbibition solution & $\triangle \rho$ & $\begin{array}{c}\text { Optimal } \sigma \\
(\mathrm{mN} / \mathrm{m})\end{array}$ & Recovery (\%) \\
\hline \multirow{4}{*}{ Water-wet } & 1 & 61.8 & - & 21.8 & Brine & 0.09 & 0.083 & 0 \\
\hline & 2 & 60.7 & 45.6 & 3.81 & $0.15 \%$ PS & 0.11 & 0.050 & 4.52 \\
\hline & 3 & 68.7 & 9.1 & 0.213 & $0.15 \%$ DBS & 0.12 & 0.036 & 6.27 \\
\hline & 4 & 66.1 & 35.4 & 0.061 & $0.15 \% \mathrm{AB}$ & 0.10 & 0.044 & 5.33 \\
\hline \multirow{4}{*}{ Oil-wet } & 5 & 114.2 & - & 25.4 & Brine & 0.09 & - & 0 \\
\hline & 6 & 118.6 & 67.1 & 3.81 & $0.15 \% \mathrm{PS}$ & 0.11 & 0.091 & 3.13 \\
\hline & 7 & 113.6 & 25.4 & 0.213 & $0.15 \%$ DBS & 0.12 & 0.038 & 4.18 \\
\hline & 8 & 119.7 & 41.4 & 0.061 & $0.15 \% \mathrm{AB}$ & 0.10 & 0.045 & 3.75 \\
\hline
\end{tabular}

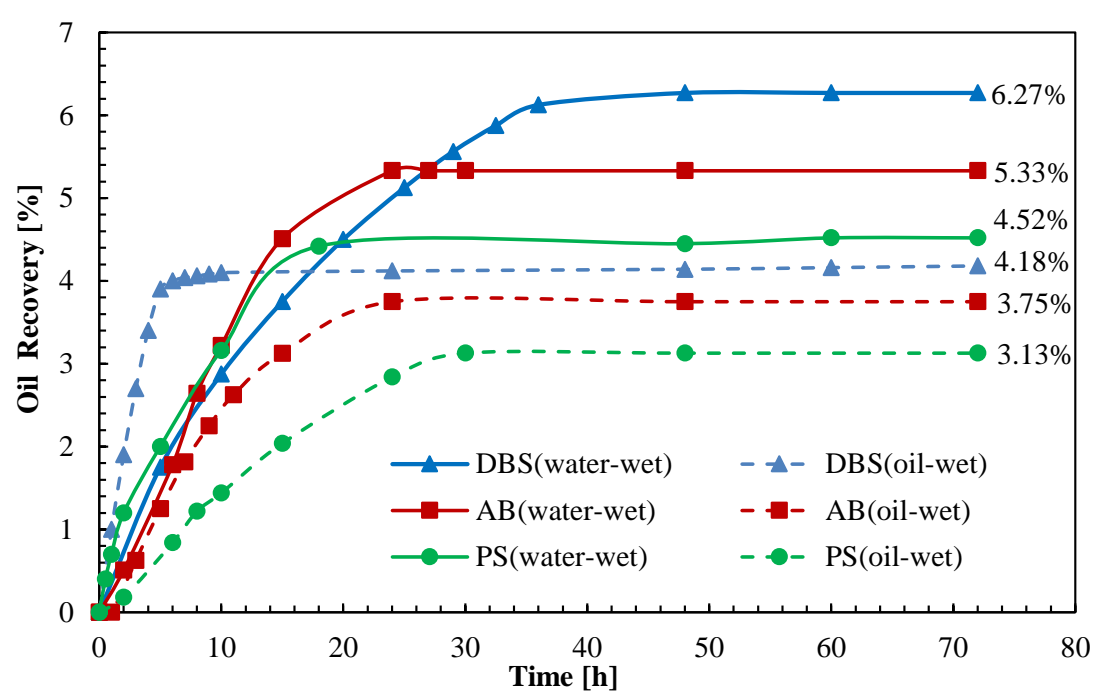

Figure 3. Relationship between oil recovery and time for spontaneous imbibition with different surfactants

The CA results in wettability alteration experiments and imbibition recovery are illustrated in Figure 4. The ability of wetting degree of the three surfactants from high to low corresponds to DBS, AB and PS. Additionally, the CA of oil-wet cores reduced to a greater extent compared to water-wet cores for all the three surfactants. The DBS performs more efficiently in wettability alteration, and the CA of water-wet and oil-wet reduced from $61.8^{\circ}$ and $114.2^{\circ}$ to $9.1^{\circ}$ and $25.4^{\circ}$ respectively. It is demonstrated that the original water-wet cores have higher imbibition recovery than the original oil-wet cores with the same surfactants (identical IFT, different CA). The cores immersed in PS, DBS and AB achieved a recovery of $4.52 \%, 6.27 \%$ and $5.33 \%$ including original water-wet respectively and accomplished a recovery of $3.13 \%, 4.18 \%$ and $3.75 \%$ with original oil-wet cores. This corresponds to $1.39 \%, 2.09 \%$ and $1.58 \%$ lower with respect to the original waterwet cores. 


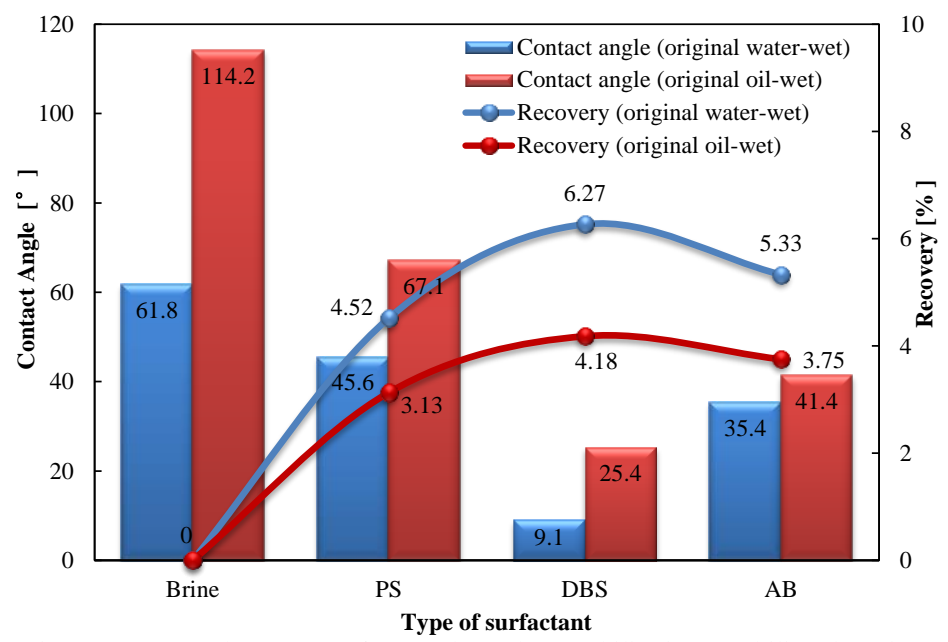

Figure 4. CA results. DBS surfactant shows better ability in wettability alteration.

\subsection{Effect of Low IFT on Imbibition Recovery}

The IFT of the three different surfactants is PS, AB and DBS in descending order, and the imbibition oil recovery of three different surfactants is DBS, AB and PS in descending order, for both original water-wet and oil-wet cores. Hence, the oil recovery of imbibition and IFT were not positively correlated. A lower IFT is not better, as it concerns spontaneous imbibition. In the chemical flooding conclusions, the IFT reduced to the most efficient magnitude of $10^{-3} \mathrm{mN} / \mathrm{m}$. Furthermore, according to the experiments, it was demonstrated that the cores have a higher recovery in lower IFT solution compared to a brine with similar CA (Cores \#1 and 6). Thus, a lower IFT is beneficial for imbibition within limits. The fact that a low value of IFT is not the best option was further confirmed by the experiments with Cores \#3, 4, 7 and 8. The surfactant $\mathrm{AB}$ with the lowest IFT $(0.061 \mathrm{mN} / \mathrm{m})$ was not as effective as DBS with an IFT of $0.213 \mathrm{mN} / \mathrm{m}$ in imbibition. According to the favorable imbibition perspective, the capillary force of water-wet cores should not be too low. A series of imbibition experiments with low-permeability (approximately $4.0 \times 10^{-3} \mu \mathrm{m}^{2}$ ) cores and surfactant solution was carried out by Yao [5], who concluded that the optical condition of imbibition, $N_{B m^{-1}}$, is slightly greater than 5 . Current research calculates the optimal IFT using Equation (2), similar to Yao et al.'s [5], with current experimental conditions including $N_{B m^{-1}}=5$. The results are presented in Table 4. The IFT of AB was located approximately at the optimal IFT, while its imbibition recovery was lower than that of the DBS solution. This indicates that the optimal condition of $N_{B m^{-}}{ }^{-1}=5$ cannot be applied to the majority of the experiments. The optimal imbibition parameters for porous media with nano-scale capillary should be further studied, while the calculation of optimal IFT or mechanism analysis should account for the surfactant properties, such as emulsification.

In capillaries area, especially in tight reservoirs where the pore size is very small (nano-scale size), the pores lead to a large viscous resistance which restrains water from imbibing into porous media and driving the oil out. Furthermore, the addition of surfactant promoted imbibition behavior. Surfactant solution lowers the IFT, facilitating the aqueous phase to penetrate into the pores and increase the deformability of the oil drop in the pores. Subsequently, the constant oil was turned into movable oil by the surfactant and participated in spontaneous imbibition. Therefore, for tight oil reservoirs, although low IFT decreases the capillary force, which is considered to be the driving force for imbibition, surfactant also had the ability to promote imbibition.

\subsection{The Imbibition Mechanism for Tight Reservoirs}

According to experiments, the driving force (buoyancy and capillary force) for porous media including small-scale pores is not large enough to overcome the resistance to produce oil in brine (Cores \#1 and 5). The water-wet core (Core \#1) also did not produce any oil, which corresponds to a different case compared to spontaneous imbibition experiments with higher permeability in literature 2,4 , and 12 . This demonstrates that the resistance for oil to flow out is greater than the driving effect of gravity and capillary force in tight cores in brine. Due to the absence of an external force in the spontaneous imbibition process, the occurrence of imbibition depends ultimately on the stress condition in the capillary. The ultra-low permeability of cores also indicates the large flow resistance in tight cores. The macro forces of imbibition in water-wet and oil-wet capillaries are presented in Table 5. In water-wet cores, the capillary force corresponds to the driving force for imbibition, while in oil-wet cores the capillary force equals the resistance for imbibition. It is considered that the imbibition will be enhanced by reducing the capillary radius, as the driving force (capillary force) increases. Nevertheless, the 
influence of the viscous force was ignored, which is also enhanced as the capillary radius decreases and presents a faster growth rate than the capillary force in small radius capillaries. Equations (5) and (6) indicate capillary force (the Laplace equation) and viscous force.

$$
\begin{gathered}
p_{c}=\frac{2 \sigma \cos \theta}{r} \\
f_{v}=\frac{8 \mu v}{r^{2}} h
\end{gathered}
$$

where $p_{c}$ refers to capillary force; $\mathrm{r}$ stands for to capillary radius; $f_{v}$ represents viscous force; $\mu$ equals fluid viscosity; $v$ is the flow velocity; $h$ corresponds to the height of capillary rise. The wall friction also represents one of the significant resistance parameters for flow, which is always ignored in normal conditions. Nevertheless, in nano-capillaries, the wall friction should be factored into the calculation, and this has been verified by past research [28]. The enhanced resistance constitutes the root cause for tight cores not imbibing in brine and presenting low imbibition recovery.

Table 5. The macro forces of imbibition in water-wet and oil-wet capillaries
\begin{tabular}{|c|c|c|}
\hline Wettability & Driving force & Resistance \\
\hline \multirow{3}{*}{ Water-wet } & $\begin{array}{c}\text { Capillary force } \\
(2 \sigma \cos \theta / r)\end{array}$ & Viscous force $\left(8 \mu \nu h / r^{2}\right)$ \\
\cline { 2 - 3 } & Buoyancy $(\Delta \rho g h)$ & Wall friction $\left(F_{f}\right)$ \\
\hline \multirow{3}{*}{ Oil-wet } & \multirow{3}{*}{ Buoyancy $(\Delta \rho g h)$} & $\begin{array}{c}\text { Capillary force } \\
(2 \sigma \cos \theta / r)\end{array}$ \\
\cline { 3 - 3 } & & Viscous force $\left(8 \mu \nu h / r^{2}\right)$ \\
\cline { 2 - 3 } & & Wall friction $\left(F_{f}\right)$ \\
\hline
\end{tabular}

Wettability alteration of surfactants can turn capillary force from a resistance to a driving force, and the driving force of imbibition is enhanced to improve the recovery for imbibition. Besides, whatever the wettability is, viscous force corresponds to the resistance and increases as capillary radius decreases. Emulsification of surfactants can reduce the viscosity of crude oil [17], increase the mobility of crude oil and reduce viscous resistance to enhance imbibition recovery. The advantage of surfactant imbibition was also proven through experiments and theory. As capillaries rise, the surface tension relaxation can induce overshot in the capillary. This means that the surfactant solution can be sucked deeper into the core, and the effect of surface tension driven flow will be enhanced in the small-scale space. Subsequently, surfactant solution reduces capillary effects responsible for trapping oil and allows gravity to segregate oil by buoyancy.

The favorable effects of low IFT and wettability of surfactant can also be explained by adhesive work. This refers to the work per unit area of separating oil from the rock wall. Equation (7) shows the relationship between adhesive work, IFT and wettability.

$$
W=\sigma(1-\cos \theta)
$$

where $\mathrm{W}$ refers to adhesive work. The effects of lower CA and IFT both favor a decrease in the adhesive work. Low adhesive work contributes to easy detachment of the oil from the solid and increases movable oil, which was also reflected in the relative permeability curve (the oil relative permeability increases and residual oil saturation decreases to enhance the oil recovery of spontaneous imbibition).

\section{Conclusions}

In this study, a series of IFT- and CA-measuring and spontaneous imbibition tests were performed to investigate the influence of lower IFT and wettability alteration on imbibition flow. Based on the results of this study, the following conclusions were drawn:

(1) The three kinds of surfactants present the effect of lower IFT and wettability alteration. Compared to the imbibition effect in brine with tight cores, the three surfactants improved imbibition recovery. Porous media presenting such low permeability are impossible to produce oil in brine, due to the increased resistance. The anionic surfactant DBS attained the optimal effect in imbibition among the three surfactants used. 
(2) Due to the small capillary, the resistance of imbibition increased, which induced a lower imbibition recovery compared to the cores of higher permeability. The viscous force increased due to capillary radius reduction, and capillary force increased at a slower rate.

(3) CA and IFT are both important factors for imbibition. The main effects of surfactant, which are lower IFT and wettability alteration, both correspond to favorable conditions for imbibition, based on the reduction of adhesive work. Concurrently, the reduction of adhesive work also corresponds to the incensement of movable oil and oil relative permeability.

\section{Acknowledgements}

This work was supported by the Major Project of China National Science and Technology "New technology of reservoir reconstruction" (2016ZX05023005) and a Subject of PetroChina Company Limited. "Research and Application of Volume fracturing design implementation and evaluation technology".

\section{Abbreviations}

$\begin{array}{ll}\text { IFT } & \text { Interfacial tension, } \sigma,(\mathrm{mN} / \mathrm{m}) \\ \text { CA } & \text { Contact angle, } \theta\left(^{\circ}\right) \\ N_{B}{ }^{-1} & \text { Inverse bond number } \\ \text { CT } & \text { Computed tomography } \\ \text { PS } & \text { Petroleum sulfonate } \\ \text { DBS } & \text { Dodecyl benzene sulfonate } \\ \text { AB } & \text { Alkyl betaine } \\ \text { WR } & \text { Wettability index } \\ \text { NMR } & \text { Nuclear magnetic resonance } \\ \text { RPC } & \text { Relative permeability curve }\end{array}$

\section{References}

1. J. O. Alvarez and D. S Schechter. "Wettability Alteration and Spontaneous Imbibition in Unconventional Liquid Reservoirs by Surfactant Additives," SPE Reservoir Evaluation \& Engineering, vol. 20, pp. 107-117, 2017.

2. V. C. Santanna, T. N. Castro Dantas, T. A. Borges, A. R. Bezerril and A. E. G. Nascimento. "The Influence of Surfactant Solution Injection in Oil Recovery by Spontaneous Imbibition," Petroleum Science \& Technology, vol. 32, pp. 2896-2902, 2014.

3. D. S Schechter, D. Zhou, \& F. M Jr. "Capillary Imbibition and Gravity Segregation in Low IFT Systems," 66th Annual Technical Conference and Exhibition of SPE, Texas, USA, 6-9 October, 1991

4. D. S. Schechter, D. Zhou, and F. M. Jr. "Low IFT Drainage and Imbibition," Journal of Petroleum Science \& Engineering, vol. 11, pp. 283-300, 1994.

5. T.Y Yao, J. S. Li, J. Wang, W.D. Liu. "Mechanisms and Optimal Conditions of Imbibition in Naturally Fractured Lowpermeability Reservoir," Journal of Jilin University (Engineering and Technology Edition), vol. 39, pp. 937-940, 2009.

6. C. C. Mattax and J. R. Kyte. "Imbibition Oil Recovery from Fractured, Water-drive Reservoir," Society of Petroleum Engineers Journal, vol. 2, pp. 177-184, 1962.

7. A. Gupta, and C. Faruk. "An Improved Model for Laboratory Measurement of Matrix to Fracture Transfer Function Parameters in Immiscible Displacement," SPE 69th Annual Technical Conference and Exhibition, New Orleans, USA, 1994.

8. D. Wang, J. Zhang, R. Butler and K. Olatunji. " Scaling Laboratory-data Surfactant-imbibition Rates to the Field in Fracturedshale Formations," SPE Reservoir Evaluation \& Engineering, pp. 440-410, 2016

9. P. P. M. Keijzer and A. S. Vries. "Imbibition of Surfactant Solutions," Society of Petroleum Engineers, doi:10.2118/20222-PA. July 1, 1993.

10. D. Wang, R. Butler, H. Liu and S. Ahmed. "Surfactant Formulation Study for Bakken Shale Imbibition," SPE Annual Technical Conference, Clolorado, USA, 30 October- 2 November, 2011.

11. D. Wang, R. S. Seright and J. Zhang. "Wettability Survey in Bakken Shale with Surfactant-Formulation Imbibition," SPE Reservoir Evaluation \& Engineering, vol. 15, pp. 695-705, 2012.

12. P. Kathel and K. K. Mohanty. "EOR in Tight Oil Reservoirs through Wettability Alteration," SPE Annual Technical Conference, Louisiana, USA, 30 September- 2 October, 2013.

13. P. Chen, K. K. Mohanty. "Surfactant-enhanced Oil Recovery from Fracture Oil-wet Carbonates: Effects of Low IFT and Wettability Alteration," SPE International Symposium on Oilfield Chemistry, Texas, USA, 13-15 April, 2015.

14. S.Berg, R.T. Armstrong, A.Georgiadis. "Onset of Oil Mobilization and Nonwetting-Phase Cluster-Size Distribution," Petrophysics, vol. 56, no. 1, pp. 15-22, 2015.

15. M. Mirzaei, D. DiCarlo and G. Pope. "Visualization and Analysis of Surfactant Imbibition into Oil-wet Fractured Cores," SPE Journal, pp. 101-111, 2016.

16. A. Alshehri and A. Kovscek. "In-Situ Visualization of Multidimensional Imbibition in Dual-Porosity Carbonates," SPE journal, pp. 1631-1643, 2016. 
17. B. Adibhatla, K. K. Mohanty. "Oil Recovery from Fractured Carbonates by Surfactant-Aided Gravity Drainage: Laboratory Experiments and Mechanistic Simulations," SPE Reservoir Evaluation \& Engineering, vol. 11, pp. 119-130, 2008.

18. J. Chen, M.A. Miller, K. Sepehrnoori. "Theoretical Investigation of Countercurrent Imbibition in Fractured Reservoir Matrix Blocks," 13th SPE Symposium on Reservoir Simulation, Taxas, 1995.

19. P. S. Gautam and K. K. Mohanty. "Matrix-Fracture Transfer through Countercurrent Imbibition in Presence of Fracture Fluid Flow," Transport in Porous Media, vol. 55, no. 3, pp. 309-337, 2004.

20. D. Kashchiev and A. Firoozabadi. "Analytical Solutions for 1D Countercurrent Imbibition in Water-Wet Media," SPE Journal, vol. 8, no. 4, pp. 401-408, 2003.

21. A. Alshehri, E. Sagatov and A. Kovscek. "Pore-Level Mechanics of Forced and Spontaneous Imbibition of Aqueous Surfactant Solutions in Fractured Porous Media," 2009 SPE Annual Technical Conferece and Exhibition, Louisiana, USA, 2009.

22. A. Paiaman and M. Masihi. "Scaling Equations for Oil/Gas Recovery from Fractured Porous Media by Countercurrent Spontaneous Imbibition: from Development to Application," Energy and Fuel, vol. 27, no. 8, pp. 4662-4676, 2013.

23. P. Ø. Andersen, S. Evje and H. Kleppe. "A Model for Spontaneous Imbibition as a Mechanism for Oil Recovery in Fractured Reservoirs," Transport in Porous Media, vol. 101, no. 2, pp. 299-331, 2014.

24. Q. Meng, H. Liu and J. Wang. "Effect of Viscosity on Oil Production by Concurrent and Countercurrent Imbibition from Cores with Two Ends Open," SPE Reservoir Evaluation \& Engineering, vol. 20, no. 2, pp. 1-9, 2016.

25. M. Delshad, N. F.Najafabadi, G. Anderson, G. Pope and K. Sepehrnoori. "Modeling Wettability Alteration by Surfactants in Naturally Fractured Reservoirs," SPE Reservoir Evaluation \& Engineering, vol. 12, no. 3, pp. 361-370, 2009.

26. M. H. Kalaei, D. W. Green and G. P. Willhite. "A New Dynamic Wettability Alteration Model for Oil-Wet Cores during Surfactant Solution Imbibition,” SPE Journal, vol.18, no. 5, pp. 109-122, 2012.

27. W. G. Anderson. "Wettability Literature Survey Part 1: Rock/Oil/Brine Interactions and the Effects of Core Handling on Wettability," Journal of Petroleum Technology, vol. 138, no. 10, pp.1125-1144, 1986.

28. A.Q. Shen, Y. Liu, X. Qiu, Y. Lu and S. Liang. "A Model for Capillary Rise in Nano-channels with Inherent Surface Roughness," Applied Physics Letters; vol. 110, pp. 1-5, 2017. 